\title{
Big Data for Educational Applications in the Urban Indian Context
}

\author{
Sujatha Ramesh ${ }^{1, *}$ and K. Natarajan ${ }^{2}$ \\ 1A-701, Westend Raheja Vihar, Chandivali Rd., Mumbai 400072, Maharashtra, India \\ Indian Space Research Organisation, Thiruvananthapuram, Kerala, India
}

\section{Article Type: Article \\ Article Citation: Sujatha Ramesh, Natarajan K. Big data for educational applications in the urban Indian context. Indian Journal of Science and Technology. 2020; 13(04), 475-485. D0l: 10.17485/ijst/2020/ v013i04/149851}

Received date: March 13, 2019

Accepted date: April 2, 2019

*Author for correspondence:

Sujatha Ramesh sujatha.natraj@ gmail.com 9 A-701, Westend Raheja Vihar, Chandivali Rd., Mumbai 400072, Maharashtra, India

\begin{abstract}
Objectives/methods: This study has discussed the implications of Big Data for education at all levels in schools and colleges of India. A system design is also presented for Big Data education in the context of the New Education Policy (NEP) of the Human Resources Development (HRD) Ministry, Government of India, which is currently being evaluated by the policy makers and academia across the nation. Findings/application: Big Data will make substantial impact on education in the years to come in conjunction with other educational technologies. This study highlights the importance of Big Data for Smart Cities and urban areas, considering educational technologies.
\end{abstract}

Keywords: Big Data, Educational Impact, NEP, Indian Context, Smart Cities.

\section{Introduction}

The amount of data generated in all walks of life including education is enormous and requires educational technologies like Big Data. Big Data and education could be a good combination, because, this will promote unique opportunities for the students in learning. In this article, we have placed accent on education based on Big Data and analyzed the advantages and problem areas. During the recent past, huge amount of data has been generated and this needs to be managed for educational applications. The Big Data market is not only regional, but global too. The international Organizations like the United Nations, the World Bank and the European Commission use tremendous quantity of data. Even in India, data usage has been exploding exponentially during the recent years. Indeed, a study has been done on the impact of computer-based education in India, way back in 1979 [1]. For engineering education, policies have been laid down by the All India Council for Technical Education (AICTE), Government of India [2-5]. According to data scientists, the data usage will increase exponentially in a decade [6]. Therefore, every small and big organization needs to create some type of data banks. 
It is proposed to establish a number of Smart Cities across the whole of India. This will ensure modern infrastructure in terms of roads and optical fiber connectivity. Thus, Big Data can be effectively used in such new urban centers. Many people have a mistaken notion about the concept of Smart Cities, imagining that these will have each and every feature of a highly modernized society envisaged in their wish list. On the contrary, the proposed cities will have some good telecommunication and road infrastructure as well as the facilities required for Swatch Bharat. Too many sophisticated facilities for every Smart City will be expensive and may not be implemented on immediate basis. Issues like garbage disposal, pollution control, bridges and passages to ensure free flow of traffic, adequate parking slots, etc. will be given importance. Two types of technologies will have the greatest impact on Smart Cities: Internet of Things (IoT) and Big Data, since any modern facilities provided are data-based and the success depends on the effective utilization of the same. Some of the Smart Cities proposed are as follows: Kochi, Visakapatnam, Bhopal, Pune, Jaipur, Indore, Udaipur, Chennai, Bhopal, Kakinada, Ludhhiyana, Jabalpur, Surat, Coimbatore, etc [7]. The list gets expanded continuously as the States demonstrate interest and action on a regular basis. The progress of these cities will be monitored too. High-tech facilities in educational institutions in Smart Cities will also promote the "Study in India" initiative of the Government of India [8].

\section{Methodology}

This investigation is based mainly on the input obtained from the New Education Policy of the HRD Ministry, which is currently being studied across the whole nation. Discussions have been held with the students and teachers of a number of schools and colleges in Chennai and Mumbai, as well as few educational technology developers, regarding the advantages and problem areas of the NEP. The secondary data from the documents and reports of UGC, AICTE, ISRO, etc [9-10] as well as the EdTech industry, gave important input to the study. The study is based on the premise that Big Data will be used in conjunction with other educational technologies like Artificial Intelligence (AI), Virtual Reality (VR), etc. for optimum realization of NEP objectives, esp. in the urban centers and Smart Cities.

\section{Big Data in Education}

In today's context, Big Data is being used at every stage of education starting from basic schools through colleges and universities [11]. The teachers will have a better feel of the students' behavior pattern, and judge them better. Using Big Data systems, institutions are in a better position to analyze the data to facilitate competent decisions [12]. The teachers will study the body language, movements, and expressions of students to help decision making process. In the United States, it is mandatory that all students in most of the grades need to be examined in few subjects using set pattern of tests. Furthermore, the states to impose their own testing patterns so that the schools as well as students and teachers are 
responsible for the performance. All these create enormous data to be handled. In India, during the recent past, and till now, there is an automatic promotion system for young children. This situation may change now. In this connection, a comparative study has been made recently, between the NEP, India and the educational system prevailing in the USA [13]. In schools and colleges, there is the problem of storage, analysis and dissemination of information between the students and teachers, necessitating Big Data techniques. Indian schools and colleges require such technologies for student enrolment, teacher evaluation, and expenditure analysis.

Big Data in education has made its presence felt in the global domain, with several programs. Some of them are as follows: (a) Program for International Student Assessment (PISA) of OECD, that monitors the skills of young students and feels, "highest performing education systems are those that combine quality with equity"; (b) the big business houses and finance industry have benefited immensely from Big Data and data analytics; (c) the pilots resorting to autopilot mode and the drivers moving around without maps are a sequel to Big Data systems. This article has studied the opportunities and limitations that Big Data presents to students, teachers, and other educational stakeholders, considering the modernized education system proposed by the HRD Ministry.

\section{System Design for Big Data Education}

The Human Resources Development (HRD) of India is in the process of restructuring education at all levels from kindergarten to doctoral programs, through the New Education Policy (NEP) [14-15]. The aims of National Educational Policy are as follows: 1. To equip students with the necessary skills and knowledge. 2. To eliminate the shortage of manpower in science, technology, academics, and industry. 3. To promote Access, Equity, Quality, Affordability, and Accountability. 4. To restructure the school curriculum and pedagogy in a new " $5+3+3+4$ design". This is going to be a major change from the legacies of the National Policy on Education, 1968, that follows the "10+2" format in the school education system. The urban students can generally adapt better to technological innovations in education.

In Ref. [16], Sujatha and Natarajan proposed a design to incorporate Big Data into the NEP-based education system. The design has ensured industry-centric curriculum, by integrating the skills and technology needs of the work-place in schools and colleges. Industry-Institute Partnership is also proposed in the context of Big Data systems to optimize syllabus and course content. The Smart Cities are highly suitable for this kind of arrangement, because, experts from the industry and academia can easily travel to these places. The purpose is that the syllabus must be relevant for the industry and that the students are exposed to relevant skill-sets needed by the industry to ensure successful integration of students with the industry and corporate world.

The System Design has incorporated not only the conventional optical fiber networks, but also the existing and proposed GSAT series satellites developed by ISRO. This will facilitate Big Data technology utilization by the student community, not only in urban areas, but also in remote hill areas of the North East, Meghalaya, and J \& K. It may be 
noted that Big Data is also used for the enormous information and images generated by the Earth Resources Satellites of India to gain good understanding of resources of India, climate change, traffic pattern, pollution, etc., in addition to education. The design will make digital classrooms a feasible proposition in educational institutions. There is scope for classrooms which are customized or tailored to the needs of the students. This will be helpful to schools where there is more number of students in relation to teachers, which the situation is prevailing in rural areas, as well as inaccessible tribal areas of India. The technology makes learning more humane. In Smart Cities, it is easier to provide devices, equipments, and facilities because they are specially designed for high-speed connectivity through optical fibers across the whole city.

In the conventional education system, students should advance based solely on their age and periodic tests. Exceptionally talented students may gain distinction, but they continue to remain in the same classes as their less gifted peers. Using Big Data systems, educators can gauge student performance continuously and students may get promoted in a fast-track mode. The main aim of integrating Big Data and any other digital technology in the education sector is to improve student performance. The management can analyze the behavior of students in classes and improve teaching-learning process, by studying their inadequacies through available data. The Big Data design will be useful for the underprivileged segment of society in education and literacy improvement. Figure 1 depicts a Flow Diagram for the NEP-based Big Data education.

\section{Educational Technologies for Smart Cities}

Smart Cities are associated with wired and wi-fi technologies. Educational Technologies are increasingly used these days in schools and colleges [17]. Technology has positive and negative impact on learning. Some students enjoy the traditional class-room style education where, they would have close interaction with the teachers. This is basically the ancient method of learning from a "guru" (teacher), where there is face to face interaction and communication. The educational technologies will remove the actual presence of teacher

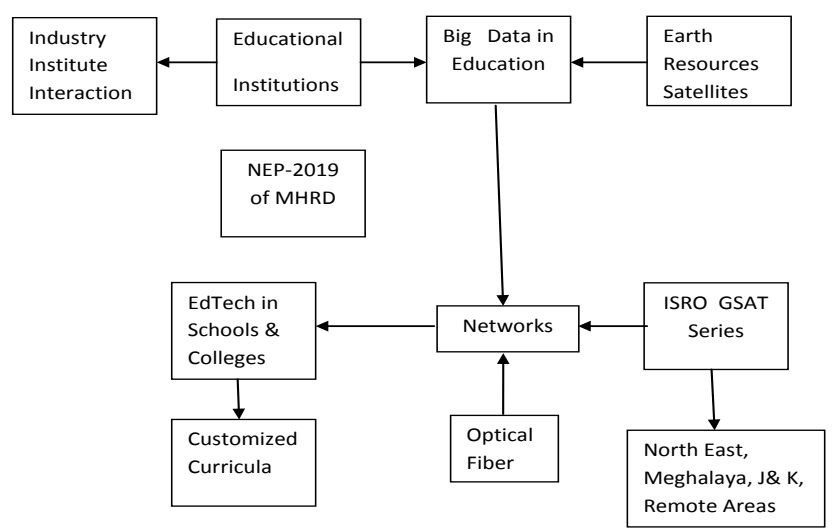

FIGURE 1. Flow diagram for NEP-based big data education. 
in many cases, since the student places his trust on the computational devices and apps. On the other hand, the modern students do enjoy the access to devices and technologies. The urban students even feel that the educational tools fill the void in their skills and capabilities. They feel that they will have a better grasp of the subjects through technologies. The educational technologies should be innovative enough to appreciate the urban cultural background, psychology and social upbringing of a student in pedagogical process. Some of the relevant educational technologies for the urban environment are as follows:

\subsection{Digital Readers and Tablets}

Nowadays, the children carry a huge luggage in the name of text books and notes. The digital readers and tablets definitely reduce this kind of physical burden on students, esp. children. They need not carry heavy backpacks. When we use a digital device, the course material can be regularly updated easily, whereas, it will be very expensive to go on buying new text books frequently. If a student adds an app to his computing equipment, he does have the advantage of personalized learning experience. However, there are few problems. The schools need to provide appropriate devices or tablets to each and every student. Occasionally, the tablets may be lost or stolen; and the teachers need to protect the students in this respect. The students who are weak in Mathematics tend to use computer devices or Tablets as a substitute.

\subsection{D-Printing}

Today, 3D printing finds extensive applications in innumerable areas such as car parts, learning geography, artificial organs, etc. Students can create their own innovative models for science projects and understand geography and maps better. This also means that the students will be unwilling to exert their brain power too much.

\subsection{Virtual Reality}

It is not possible for a student to visit every factory or institute to learn new techniques. Some of the fabrication facilities may not even be available anywhere in the country because of expensive installation costs. In order to facilitate learning such complex and expensive technologies, augmented reality, virtual reality, etc. are being resorted to, so that the student gets a reasonable understanding of these, through virtual trips to industries. Indeed, a student can also embark on virtual tours to ancient Mexican Egyptian or Indus Valley civilizations through AR and VR, to get a real-life experience. This is better than gaining mere theoretical knowledge. However, virtual reality has a problem in getting a correct feel of special dimension. He may dream in an imaginary world, removed from reality of life. Some students get into motion sickness, where the eyes move but the body does not.

\subsection{Gamification}

Many students study better if they find study fun like games. The course content can be learnt with ease through gamification, and the students become enthusiastic. The use of 
gaming in the classroom applies this concept by tying together the fun part of play with the content and concepts that students must learn. However, many games are not effective. The games need training to use them properly in classrooms.

\subsection{Cloud Technology}

The advantage of clouds is that services and apps can be linked to the Internet rather than one's computer. Thus data can be accessed on any device or equipment that is connected to the Internet. For educational purposes, lessons, assignments, and textbooks can be stored and retrieved from the net onto a device. The students can also chat live with the teachers using the cloud. The lectures can be watched via the net even before the class, which can be used for meaningful discussions, in a "flipped classroom". The students need not carry heavy text books or note-books. The students can access information easily on a device at his convenience. The student can access the teacher easily and quickly through chat mode. The main problem for the student is that his school should have good connectivity. Hacking can also be a problem despite security provided by school.

\subsection{Artificial Intelligence (AI)}

AI has been used extensively in all walks of life. Students' grading can be done effortlessly through AI. Parking can be guided carefully. Customized learning is possible through AI. A good account of the impact of AI on education is given in Ref. [18].

\subsection{Mobile Devices}

These days, almost every student has a mobile device. Using apps, subjects like Maths, Sciences, and even languages can be learnt. Students can interact with the teachers through Skype. Thus, learning at the time of convenience to students and teachers has become possible, facilitating greater flexibility in teaching-learning process.

\section{Big Data Payoff in Education}

Some of the benefits resulting from Big Data in education, esp. in the Smart Cities environment are as follows:

- Improved performance of students in schools to ensure enhanced chance of admission in good colleges or universities.

- Accurate assessment of students by studying their progress continuously.

- Better performance of educational institutions.

- Development of new educational patterns such as curriculum customized to the needs and novel digital learning methods.

- Identification of problem-areas of students using Big Data along with Adaptive Learning.

- Use of conventional class rooms along with online learning process. 
- It is not enough if students know only a few subjects taught in schools. Over the years, there have been concerted efforts by the HRD Ministry, schools, parents, and other stakeholders towards holistic development of learners. The idea is to impart the students, additional skills and extra-curricular activities to add on to their academic competencies.

- With Big Data, schools can track their students' performance across several disciplines both at an individual and collective level and develop relevant solutions to assist in progress by teaching them new skill sets.

- All over India, tens of thousands of people want to do higher education. Colleges find it difficult to accommodate all of them. With Big Data and other educational technologies, however, they can register thousands of students in distance or online programs. In Tamil Nadu, Annamalai University has been running online courses for several years. In All India level, BITS, Pilani and its various Campuses have some kind of Distance-

- Education programs. In addition to reduced cost of education, we do not need too many class rooms and teachers. In urban areas, it is easier to conduct special training sessions for students.

- Today, in schools and colleges, there are too many tests and students. However, for this situation, the number of teachers looking after them is not proportionately high.

- In some village schools, there are just two or three teachers. Grading a large number of students using very few teachers is not practical. Big Data facilitates teachers a faster and more convenient way to grade the student community.

\section{Satellites Big Data and 5G Tech: Role of ISRO Satellites}

In this Space Age, Big Data is possible through a series of satellites, esp. in view of the low cost of satellite technology for huge data utilization [19]. Besides, satellite connectivity is possible not only in urban areas and Smart cities, but also in rural areas. The satellites orbits at 160 to 2000 kilometers are Low Earth Orbits (LEO) and provide enormous data each day. The satellite images are analyzed by computers using Machine Learning (ML) algorithms through which required information is retrieved. We use Artificial Intelligence (AI) too in conjunction with ML to effectively utilize the space data. ISRO's GSAT-11 satellites would facilitate internet connectivity at good speed in the NE Region as well as hilly terrains, along with Bharat Net. GSAT-11 comes with 32 transponders in the Ku band and eight in the Ka band. The high-throughput satellite (HTS) together with two smaller HTS satellites GSAT-19 and GSAT-29 launched earlier would offer satellite-based broadband services in rural and remote regions and would use the efficient Ka frequency band [20]. The Department of Telecommunications (DoT), under the phase-II of the BharatNet program, aims to connect as many as 6000 gram panchayats or village blocks in North East and J\&K having unfriendly terrain with satellite-based bandwidth. BharatNet is now nearing completion. These Satellite Big Data initiatives will help in providing education for most of the people, not just the urban students, but also the ones residing in hill areas and remote villages. 
Education will be influenced by the $5 \mathrm{G}$ technology that is going to be a new mobile revolution in the near future. The Smart Cities are indeed, designed for such highspeed technologies. Through 5G technology, one can use worldwide cellular phones as well as enormous capability to handle data [21], and provides $25 \mathrm{Mbps}$ connectivity and supports virtual private network. 5G technology has extraordinary data capabilities and has ability to tie together unrestricted call volumes and huge data broadcast within latest mobile operating system. 5G technology has a bright future because it can handle best technologies and offer attractive features to their customers. The $5 \mathrm{G}$ technology provides up to $25 \mathrm{Mbps}$ connectivity and also supports virtual private network. 5G technologies have an extraordinary capability to support Software and Consultancy. The Router and switch technology used in 5G network provide high connectivity. The 5G technology distributes internet access to nodes within the building and can be deployed with the union of wired or wireless network connections. The current trend of 5G technology has a glowing future. Needless to say, $5 \mathrm{G}$ will be used extensively in urban education, in conjunction with Big Data technology and satellites.

\section{Impact of Big Data on Smart Cities and Education}

Every facility required by modern cities requires huge data. A good example of a Smart City is Songdo in South Korea situated about $70 \mathrm{~km}$ from Seoul. This city is completely wired and every kind of Internet service is provided at high speed, facilitating proper implementation of IoT and Big Data. Traffic is monitored continuously through digital devices to avoid congestion. The layout of housing colonies is elegant. Clearly, the Big Data manipulation using appropriate techniques will result in improved lifestyle for urban Indians due to better control in the following domains, all of which will encourage creation of new educational and training institutions to benefit the students and teachers, who will migrate to the Smart Cities [22]:

\subsection{Emission Control}

There will be sensors fitted in vehicles as well as roads everywhere in the Smart City. The total traffic flow in a locality will be recorded. The emission will be monitored at different points to ensure that pollution in the city is within reasonable limits. In case, there is excessive pollution in a given area, the traffic will be re-routed such that all the areas of the city are safe from pollution point of view. Big Data will assess the emission and pollution in the time and space domains in the city to facilitate intelligent decision making.

\subsection{Parking Slots}

In every city in India, the major problem is the parking of vehicles. In Smart Cities, all the vehicles and parking areas will have appropriate sensors fitted in. In case, a given parking area has no slot, the cars will be directed to the nearest parking area, where there are slots available. The parking slots can also be booked online using apps so that they can be allotted in an organized fashion. 


\subsection{Wi-fi Network}

An efficient wi-fi network can be developed involving IoT and Big Data by placing towers at right places and battery energy can be conserved for mobile devices.

\subsection{Flexible Land Use}

Compatible activities will be allocated to one area so that the facilities required by them can be shared economically. Housing will also be developed according to user needs of groups.

\subsection{Road Networks}

Road networks can be created in accordance with traffic needs, providing pathways for cyclists and pedestrians.

\subsection{Underground Networks}

The electricity power lines can be elegantly placed in serviceable underground networks. Separate fiber and telecommunication networks can also be created beneath the roads. Similarly, storm water and drainage networks can also be suitably placed beneath the roads. Thus, roads will have elegant look and bridges and elevated tracks can be easily created without obstructions.

\subsection{Modernized Educational Institutions}

Most of the educational institutions require good communication network and highspeed connectivity. The Smart Cities are specifically designed to facilitate these. The 5-G services can be planned and established in a cost-effective way by proper installation of optical fiber network, satellite ground stations, wi-fi towers, telecommunication networks, etc. These will help in the creation of cutting-edge technologies required for Ivy- League class of institutes in India. India will emerge as educational destination for the world, with affordable cost of education. "Study in India" initiative proposed by the Hon. Prime Minister of India will, and then become a reality. In each Smart City, specialization in education can be done on domains unique to the city: such as furniture, fine arts, tourism, hotel management, health sciences, computer technologies, metallurgy, steel, minerals, water conservation, solar energy, organ transplant, stem cells, automobiles, aeronautics, nanotechnology, etc. A number of transportation modes like apps-driven cabs, shared services, Metro Trains, etc. will make education a pleasure for the students, by reducing congestion in buses.

\subsection{Good Governance}

Smart Cities will result in good governance because of improved online and digital activities in all spheres of day-to-day life of a citizen. The land records can be digitized and 
centralized. The property ownership, issue of "pattas" for land, etc. will be free from illegal or "benami" occupation by unauthorized persons.

\subsection{Public Spaces}

Parks, recreational facilities, playgrounds, etc. can be created. Public paces can be allotted for common social festivals, meetings, etc.

\section{Limitations of the Study}

- We believe that, given the diversity in India, Big Data alone will not solve problems in the education systems. In our country with varied languages, excessive reliance on Big Data will be counter-productive.

- In India, there are hundreds of AICTE approved engineering colleges. However, most of the Colleges do not produce students highly skilled in Big Data technologies required by the industry.

- Big Data needs to address scalability and storage problems.

- Big Data, by nature, deals with massive volumes of data. In India, a typical College or University has several thousand students. So, data losses may pose problems, esp. in the context of cloud storage.

- In the process of keeping multiple datasets of the entire student population across several categories, errors such as data losses can occur. These are especially common in cloud storage systems and can be quite expensive to correct. We need a large number of experts to address such issues like data errors.

- Data safety is an important problem in Big Data.

\section{Conclusion}

This study has attempted to evaluate Big Data and other Educational Technologies for urban environment in the context of NEP of the HRD Ministry, in order to optimize students' performance in schools and colleges from kindergarten to doctoral programs. This study is particularly relevant for students in Smart Cities, where state-of-the art ICT infrastructure is envisaged. Big Data has not evolved fully in India. Still, it will play substantial role in the teaching-learning processes of the schools and colleges, in the years to come. The existing and proposed ISRO GSAT Satellite series, when fully operational, will also play a significant role in Big Data education in Smart Cities and will be supported by Bharat Net, in conjunction with the conventional optical fiber network. Furthermore, the unique features of $5 \mathrm{G}$ technology will help the NEP. Big Data education will ensure that exceptional students may go for advanced courses in fast-track mode, while greater flexibility is offered to suboptimal students. 


\section{References}

1. A techno-economic feasibility study. http://www.holtecnet.com/index.php?id=57. Date accessed: 2013.

2. PCAST, executive office of the president, the president's council of advisors in science and technology report. 2010, 1-148.

3. Hey T, Tansley S, Tolle K. The fourth paradigm: data-intensive scientific discovery. Microsoft Research: Redmond, Washington. 2009.

4. Strawn GO. Scientific research: how many paradigms? EDUCAUSE Review. 2012; 47(3), 26-34.

5. AICTE, policies for UG and PG, All India Council for Technical Education. https://www.aicteindia.org/. Date accessed: 2017.

6. Smart data collective. https://www.smartdatacollective.com/. Date accessed: 2019.

7. GOI, Govt. of India, Smart Cities Mission, Ministry of Housing and Urban Affairs. http:// smartcities.gov.in/content/innerpage/smart-city-features.php. Date accessed: 12/04/2017.

8. GSAT-11 satellite to boost Internet connectivity in North East: Manoj Sinha. Telecom News. https://telecom.economictimes.indiatimes.com/news/gsat-11-satellite-to-boost-dataconnectivity-in-north-east-manoj-sinha/66951883. Date accessed: 05/12/2018.

9. UGC: Govt. of India, Report of the higher education in India: issues related to expansion, inclusiveness, quality and finance. University Grants Commission: New Delhi. 2019.

10. Allerin. https://www.allerin.com/blog/4-ways-big-data-is-transforming-the-education-sector. Date accessed: 01/01/1970.

11. Dede C. Data-intensive research in education: current work and next steps. Computing Research Association: Arlington, VA. 2015; 1-20.

12. Sujatha R, Natarajan K. New education policy of India: a comparative study with the education system of USA. International Journal of Humanities and Social Science Invention. 2019; 8(6), 01-09.

13. MHRD, National Education Policy: NEP, 2019, Draft National Policy, Ministry of Human Resources Development, Government of India. https://MHRD.gov.in. Date accessed: $18 / 11 / 2019$.

14. NEP, new education policy-2019, news in educational tips \& tricks, https://niosdelednews. in/2019/06/02/new-education-policy-2019-pdf-download/. Date accessed: 02/06/2019.

15. White house office of science and technology policy. Investing in America's future: preparing students with STEM skills. 2015; 1-9.

16. Sujatha R, Natarajan K. Integrating educational technologies into engineering education in Indian technical universities. Journal of Advanced Research in Dynamical and Control Systems, USA. 2019; 11(10), 125-131.

17. Sujatha R, Natarajan K. Artificial intelligence for educational applications in the context of Prime Minister's New Education Policy (NEP). In: International conference on recent trends in computing, communication \& networking technologies. 2019; 4.

18. Muntazir Abbas. ET telecom. https://telecom.economictimes.indiatimes.com/author/ 479234376/muntazir-abbas. Date accessed: 30/10/2013.

19. Features of $5 \mathrm{G}$ technology. http://freewimaxinfo.com/5g-technology.html. Date accessed: 2019.

20. How big data helps build smart cities. Tech Alpine, K Dnuggets News. https://www.7wdata.be/ article-general/how-big-data-and-internet-of-things-builds-smart-cities/. Date accessed: 2015. 